\title{
Clinical experience of SIB-IMRT in anal cancer and selective literature review
}

\author{
Stefan Janssen ${ }^{1}$, Christoph Glanzmann ${ }^{1}$, Peter Bauerfeind ${ }^{2}$, Sonja Stieb ${ }^{1}$, Gabriela Studer ${ }^{1}$, Michelle Brown ${ }^{1}$ \\ and Oliver Riesterer ${ }^{1 *}$
}

\begin{abstract}
Purpose: To evaluate feasibility and outcome of our institutional SIB-IMRT schedule in patients with anal cancer and to selectively review the literature on different SIB-IMRT schedules.

Patients and methods: Between 01/08-06/13 25 patients with biopsy proven squamous cell anal cancer were treated in our institution with IMRT. Radiotherapy was delivered in two series using a SIB-IMRT schedule of $45 \mathrm{~Gy} / 1.8 \mathrm{~Gy}$ to the primary tumor and adjacent pelvic lymph nodes and $38 \mathrm{~Gy} / 1.52 \mathrm{~Gy}$ to elective nodes followed by an IMRT boost of 7×2 Gy = 14 Gy to the primary tumor and involved nodes (cumulative prescription dose: 59 Gy).

Results: Mean follow-up was 20 months (range: 4-68). The 2-year-local control, colostomy-free survival, distant metastases-free survival and overall survival rates were 92\%,92\%,92\%, and 88\%, respectively. Grade 3 acute skin toxicity was observed in 6 patients (24\%). No high grade gastrointestinal or urinary acute toxicity occurred. Four patients required more than one day of treatment interruption due to acute toxicity. No grade 3 or higher late sequelae were observed.
\end{abstract}

Conclusion: We present our institutional SIB-IMRT experience treating patients with anal cancer in two series using moderate single doses from 1.5-2.0 Gy. Our results, in terms of loco-regional outcome and toxicity, were comparable to other studies. The incidence of treatment interruptions was very low. Therefore this schedule appears to be safe for clinical use.

Keywords: SIB-IMRT, Anal cancer, Definitive radio-chemotherapy

\section{Introduction}

Anal cancer is rare with an incidence of only 1-2/ 100.000 [1]. Since Nigro et al. observed high rates of response in the neoadjuvant setting, organ preserving definitive radio-chemotherapy has been the standard of care [2]. Randomized phase III trials confirmed superiority of concurrent radio-chemotherapy using 5-fluorouracil (5-FU) and mitomycin C (MMC) compared to radiotherapy alone $[3,4]$ or platinum-based radio-chemotherapy [4].

The loco-regional control rates of patients treated with radio-chemotherapy in randomized phase III trials ranged from $61 \%$ to $84 \%$ after 5 years [3-5]. In RTOG 98-11 major acute $\mathrm{G} 3$ or higher toxicities were skin reactions (49\%), hematologic effects (61\%), and gastrointestinal

\footnotetext{
* Correspondence: oliver.riesterer@usz.ch

'Departments of Radiation Oncology, University Hospital Zurich, Rämistrasse 100, CH-8091 Zurich, Switzerland

Full list of author information is available at the end of the article
}

toxicities (37\%). Major late G3 or higher toxicities were skin reactions (3\%) and gastrointestinal problems (3\%) [5]. So far, all prospectively randomized phase III studies on radiation therapy of anal carcinoma used 3-D conformal radiotherapy [3-5]. In recent years, several multi- and single institution studies demonstrated that intensitymodulated radiotherapy (IMRT) reduced toxicity without compromising outcome [6-12]. The use of highly conformal IMRT for treatment of anal cancer is attractive because of the large treatment volumes adjacent to the small bowel and bladder as well as exposure of the skin in the gluteal fold to high doses. A recent prospective RTOG phase II trial (RTOG 0529) investigated the utility of IMRT in anal cancer. The 2-year loco-regional control rate was $80 \%$. In comparison to the results of RTOG 98-11 the use of IMRT reduced early G3 or higher gastrointestinal toxicity from $36 \%$ to $22 \%$, and G3 or higher skin toxicity from $47 \%$ to $20 \%$ [13]. However, 
until long term control rates become available, concerns remain regarding potential compromise of tumor control rates using more conformal radiotherapy. IMRT can be delivered in several consecutive series using cone-down boost technique but also offers the possibility to deliver treatment giving different doses to different target volumes at the same time (simultaneously integrated boost (SIB) or "dose painting"). The optimal technique of IMRT with or without SIB is still under debate, because the use of a SIB requires altered fractionation schedules that might compromise tumor control, if too low dose per fraction is used, or increase toxicity if doses above 2 Gy fractions are used. Up to date no standard SIB IMRT schedule has been established.

Here we present the outcome of 25 anal cancer patients treated consistently with our institutional SIB-IMRT schedule. Additionally we undertook a selective literature review on clinical studies investigating different SIB-IMRT schedules for treatment of patients with anal cancer.

\section{Patients and methods Patients}

From 01/2008 to 06/2013 25 patients with biopsy proven squamous cell anal cancer were included in the analysis (Table 1).

All patients alive at the time of analysis were contacted by telephone (S.J.) or were recently seen in our department for regular follow-up visits. Additional information

\section{Table 1 Patient related parameters}

\begin{tabular}{ll}
\hline Age & \\
Mean age (years) & 61 \\
Range & $41-90$ \\
Gender & \\
Male & $16(64 \%)$ \\
Female & $9(36 \%)$ \\
Tumor stage & \\
T1 & $3(12 \%)$ \\
T2 & $12(48 \%)$ \\
T3 & $8(32 \%)$ \\
T4 & $2(8 \%)$ \\
Nodal stage & \\
N0 & $13(52 \%)$ \\
N1 & $6(24 \%)$ \\
N2 & $4(16 \%)$ \\
N3 & $2(8 \%)$ \\
Distant metastases & \\
M0 & $25(100 \%)$ \\
M1 & $0(0 \%)$ \\
\hline
\end{tabular}

was obtained from general practitioner and attending specialist. Patient and treatment related parameters are summarized in Tables 1 and 2.

\section{SIB-IMRT}

All patients underwent a planning-CT in supine position. Gross tumor volume (GTV) was defined as macroscopic disease (primary with/without lymph nodes). Elective node regions such as inguinal and iliacal, obturator and presacral lymph nodes were delineated as clinical target volumes (CTV). The GTV was expanded by at least $2 \mathrm{~cm}$ and the CTV by $1 \mathrm{~cm}$ for the planning target volume (PTV). A second planning CT was performed around 40 Gy for definition of the boost volume. The boost PTV usually contained a margin of at least $2 \mathrm{~cm}$ from the primary tumor and $1-2 \mathrm{~cm}$ from the nodal GTV.

SIB-IMRT was performed using the following institutional standard schedule:

$1^{\text {st }}$ series: 45 Gy in 1.8 Gy single doses to the pelvis, involved lymph nodes (PTV1) and lymph nodes at high risk for microscopic disease (usually lower internal and external iliac nodes) and 38 Gy in 1.52 Gy single doses to elective nodes (PTV2). Elective nodes were mainly uninvolved inguinal and upper internal iliac nodes.

$2^{\text {nd }}$ series: IMRT boost of $7 \times 2=14$ Gy given to the primary tumor and lymph node metastases (total prescription dose: 59 Gy). In 2 patients with low risk tumors the

Table 2 Treatment related parameters

\begin{tabular}{ll}
\hline Postoperative IMRT & $2(8 \%)$ \\
Definitive IMRT & $23(82 \%)$ \\
RT dose & $25(100 \%)$ \\
Series 1 SIB: 45 Gy SIB & \\
IMRT (25x1.8/1.52 Gy) & \\
Series 2 Boost: & $20(80 \%)$ \\
7x2=14 Gy (total: 59 Gy) & $1(4 \%)$ \\
7x2.1 = 14.7 Gy (total: 59.7 Gy) & $1(4 \%)$ \\
$8 \times 1.8=14.4$ Gy (total: 59.4 Gy) & $1(4 \%)$ \\
6x1.8 = 9.8 Gy (total: 55.8 Gy) & $2(8 \%)$ \\
5x1.8 = 9 Gy (total: 54 Gy) & $4(16 \%)$ \\
Treatment breaks >1 day & $21(84 \%)$ \\
Concomitant chemotherapy (5-FU and MMC) & \\
Mean treatment volumes (ccm, range) & $33.2(6-103)$ \\
GTV & $1042.9(248-3222)$ \\
PTV38 Gy & $1483.3(482-2874)$ \\
PTV45 Gy & $335.1(56-666)$ \\
PTV59 Gy & \\
\hline IMRT: intensity modulated radiotherapy, SIB: simultaneously integrated boost, \\
GTV: gross tumor volume, PTV: planning target volume.
\end{tabular}


boost was reduced on an individual basis to a total dose of 54 Gy (Figure 1).

For treatment planning, the dose was normalized to the mean dose in PTV1. For intensity optimization, the prescribed dose encompassed at least $95 \%$ of the PTV. Additionally, no more than $2 \%$ of any PTV received $>110 \%$ of its prescribed dose, whereas no more than $1 \%$ of any PTV received $<93 \%$ of the prescribed dose. Irradiation was delivered with four to five coplanar beam angles by a 6-MV dynamic MLC system (Varian Medical Systems, Palo Alto, CA) using a sliding window technique, or using volumetric modulated arc technique (VMAT, $\mathrm{n}=19$, since 10/2010).

\section{Systemic therapy}

Systemic therapy preferably consisted of concomitant 5fluorouracil (5-FU) day $1-5\left(750 \mathrm{mg} / \mathrm{m}^{2}\right.$, maximum absolute dose: $1500 \mathrm{mg}$ ) and mitomycin C (MMC) day 1 $\left(10 \mathrm{mg} / \mathrm{m}^{2}\right.$, maximum absolute dose: $\left.20 \mathrm{mg}\right)$ in week one and five $(\mathrm{n}=21)$. In 5 patients, chemotherapy was reduced or stopped after the first cycle due to blood count changes and/or reduction of general condition. Four patients did not receive any systemic therapy due to age and/or reduced Karnofsky performance score $(\mathrm{n}=2)$ or postoperative setting $(\mathrm{n}=2)$.

\section{Assessment of toxicity}

Acute and late toxicity was assessed according to the Common Terminology Criteria for Adverse Events (CTCAE) version 4.0.

\section{Statistical analysis}

Kaplan Meier survival analyses were performed using SPSS version 21.

Analysis was approved by the ethics committee of the Zurich university hospital.

\section{Results}

\section{Disease control}

The mean follow-up time was 20 months (range: 4-68). The 2-year local control, disease free survival, colostomyfree survival, metastasis-free survival and overall survival rates were $92 \%, 92 \%, 92 \%, 92 \%$ and $88 \%$, respectively (Figure 2).

At the time of analysis, 3/25 (12\%) patients were dead. In two cases this was tumor related due to primary tumor progression $(n=1)$ or distant metastases $(n=1)$, whilst the third patient died from a progressive lung cancer.

An 86 year old patient with a stage T2N0G3 cancer treated with chemoradiation to 59 Gy developed a local recurrence 10 months after RT completion. A salvage
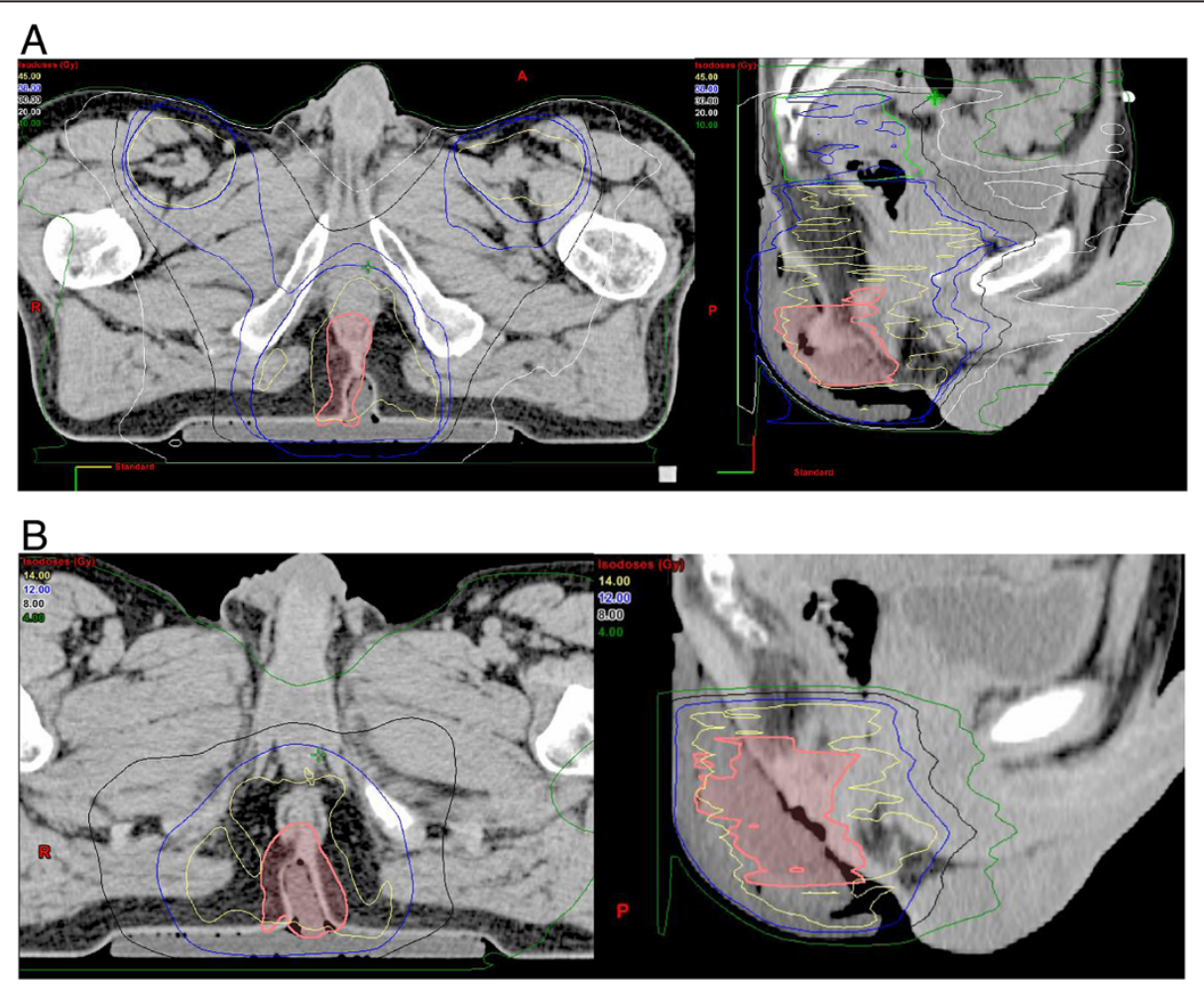

Figure 1 SIB-IMRT plan. (A) SIB-IMRT plan for a 47-year old male anal cancer patient (CT2CNOM0). Light green: 38 Gy, blue: 45 Gy pelvis field. (B) IMRT boost volume, second series to the tumor. Yellow: 14 Gy. Pink: GTV. 


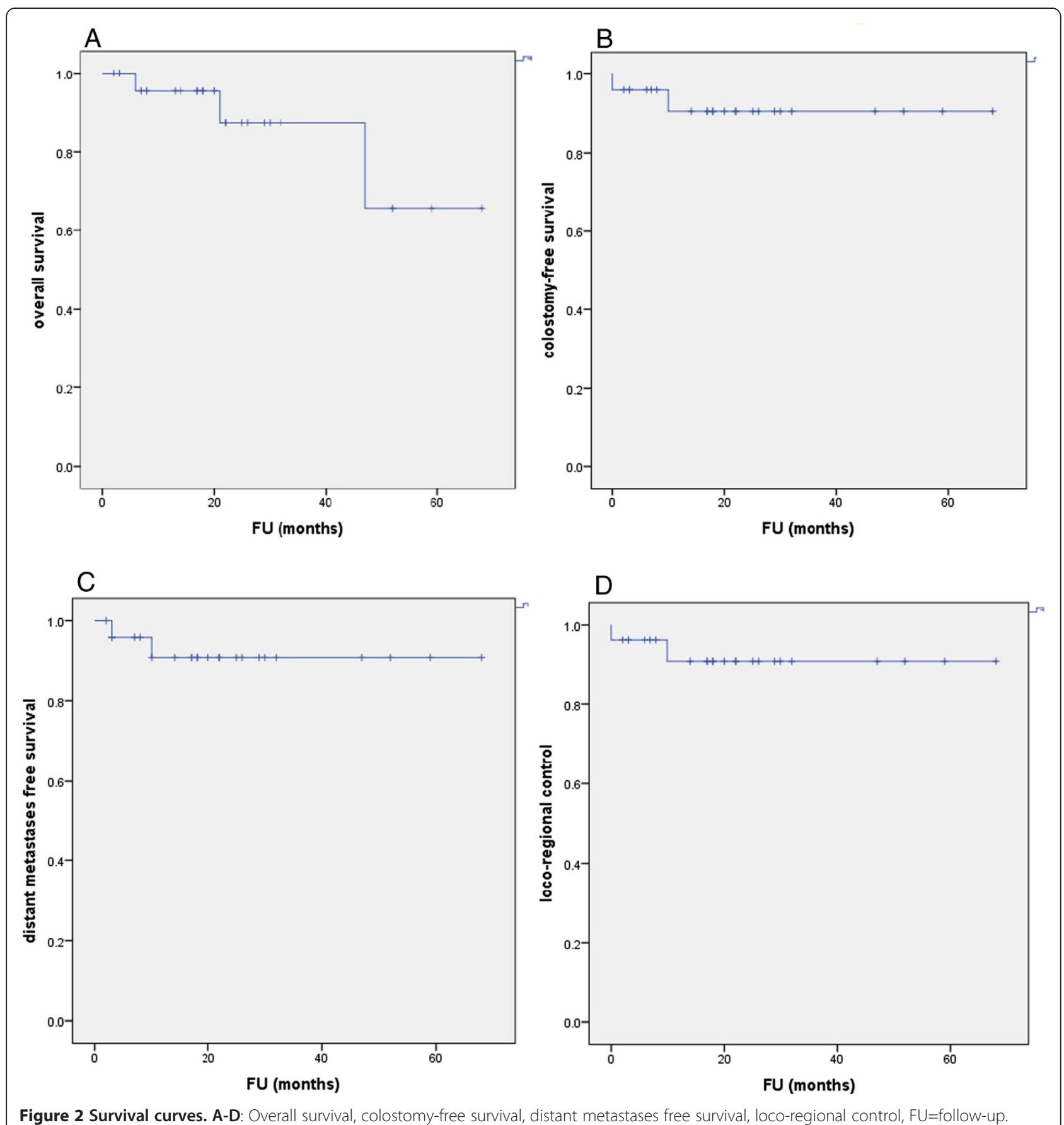

colostomy was carried out. The patient is still alive and free of disease. A 61 year old female patient with a stage T3N0G2 cancer treated with chemoradiation to 59 Gy suffered from tumor persistence and died 21 months after RT completion due to reduced general condition/ local and distant tumor progression. One patient developed lung metastases three months after completion of radio-chemotherapy and died due to distant tumor progression after 3 months.

\section{Early radiation induced side effects}

Grade 3 acute skin toxicity was observed in 6 patients $(24 \%)$ and grade 3 acute hematologic toxicity in 4 patients (16\%). No other grade 3 or higher acute toxicity was seen. If only patients with radio-chemotherapy were considered acute grade 3 skin and hematologic toxicity was seen in 5/21 (24\%) and 4/21 (19\%), respectively. 15 patients had no treatment breaks. Six patients had one single day of therapy interruption, 2 
patients 2 days and one patient missed 3 and 4 days, respectively.

\section{Late tolerance}

Late toxicity was reported as grade I proctitis in one patient 18 months post IMRT completion, one patient suffered from intermittent diarrhea 14 months after completion of radio-chemotherapy and another patient had a slight insufficiency of sphincter muscle (22 months after IMRT). No grade 3 or higher late sequelae were observed.

\section{Discussion}

Patients with anal cancer have been treated with organ preserving radio-chemotherapy since the findings of Nigro et al. [2]. Radio-chemotherapy is superior to radiotherapy alone [3]. Efforts to replace MMC by cisplatin have not been beneficial in terms of tumor control [5]. As loco-regional control rates of up to $84 \%$ at 5 years are acceptable, a major focus is reduction of treatment related side effects which have been remarkably high with acute $\geq$ grade 3 hematologic toxicity of $26 \% / 61 \%$, skin reaction of $48 \% / 49 \%$ and gastrointestinal toxicity of $16 \% / 37 \%$ in UK anal cancer trial (ACT II) and RTOG 98-11, respectively $[5,14]$.

IMRT is a technique to deliver radiotherapy with modulated beams holding the chance to deliver highly conformal doses to the target volume while sparing organs at risk. Several series beginning in the early 2000`s reported their experiences with IMRT in anal cancer treatment.

\section{Side effects}

Studies comparing results of patients treated with IMRT and 3-D plans identified reduced major acute and late non-hematological toxicities without a compromise in outcome $[6,7,9]$. As an example, Chuong et al. found a reduction of acute $\geq \mathrm{G} 3$ non-hematologic toxicity of almost $40 \%(\mathrm{p}=<.0001)$. Menkarios et al. and Brooks et al. showed a significantly reduced dose to small bowel, bladder and genitalia compared to 3-D planning [10,11]. The study groups of Salama and Kachnic evaluated IMRT in comparison with historic standards and confirmed significant reduction of acute and late toxicity [8,13]. In the RTOG 0529 phase II IMRT study, there was a significant reduction of acute grade $2+$ hematologic ( $73 \%$ vs. $85 \%)$, grade $3+$ gastrointestinal ( $21 \%$ vs. $36 \%)$ and grade $3+$ dermatologic adverse events (23\% vs. $49 \%)$ in comparison to the results of RTOG-98-11 [15]. In terms of efficacy and toxicity our results also compare favorably with the randomized trials using 3-D-conformal techniques and are comparable to recent IMRT studies (Table 3). Before the IMRT era anal cancer patients in our institution were treated with 3-D conformal 45 Gy to the pelvis plus 14.4 Gy photon boost or 14 Gy high dose rate brachytherapy with Ir192 (in 7 fractions). In published results of 81 patients overall acute grade 3 or 4 toxicity of 43\% (photon boost) and 15\% (brachytherapy boost) was observed. Chronic toxicity occurred in 19\% (brachytherapy boost) and 30\% (photon boost) [16]. In the current IMRT series we observed acute grade 3 skin toxicity in only $24 \%$ of patients. Only 3 patients complained about low grade late toxicity and no grade 3 or higher late sequelae were seen. Response rates in both series are comparable.

\section{Treatment breaks}

In comparison to other published results, the treatment breaks in our patient cohort were considerably low with only $8 \%$ of patients in need of more than 1 day of treatment break due to acute toxicity. These data reflect the good tolerability of our approach. Salama et al. found breaks in $41.5 \%$ of patients, lasting a median of 4 days [8]. Bazan et al. reported on 34.5\% treatment breaks with IMRT, which was significantly less than with 3-D planning (88\%) [7]. In RTOG 98-11, treatment breaks were reported in $62 \%$ and were mainly required secondary to radiation toxicities. One reason for low acute skin toxicity in our patients could be sophisticated nursing with specially trained nursing staff provided in our outpatient clinic. As treatment breaks are shown to compromise treatment outcome in anal cancer patients $[17,18]$, this is an important finding.

\section{SIB-IMRT in anal cancer patients}

IMRT, in principle, enables delivery of different doses to different target volumes (e.g. pelvic and inguinal lymph nodes) in the same treatment session (SIB, "dose painting"). This leads to a shortening of the treatment course. In addition, only one or two physic plans have to be generated and approved. There is still concern regarding the use of a SIB technique in anal cancer because more conformal dose distribution and altered dose per fraction might compromise outcome and/or increase toxicity.

As summarized in Table 3, several different SIB IMRT schedules are described in the literature. In some studies, the total dose varied according to $\mathrm{T}$ stage $[12,13]$. Most studies administered SIB in only one series whereas 4 studies conducted 2 series $[7,8,10,19]$. SIB dose per fraction ranged from 1.28 Gy to 2.25 Gy and total doses from 30.6 Gy to 59.4 Gy. When we implemented IMRT in anal cancer, we decided to deliver SIB-IMRT carefully in 2 series with single fractions of maximally $2 \mathrm{~Gy}$, because we did not want to risk increased toxicity. In comparison to many US centers and the RTOG trials, in which $45 \mathrm{~Gy} /$ 50.4 Gy were given to T1/T2 and 55-59 Gy/54 Gy to T3/4 
Table 3 Different SIB-IMRT schedules in treatment of anal cancer

\begin{tabular}{|c|c|c|c|c|c|c|c|c|c|c|}
\hline Study/year & Patients & $\begin{array}{l}\text { Mean FU } \\
\text { (months) }\end{array}$ & $\begin{array}{l}\text { SIB-IMRT dose levels } \\
\text { (prescription total dose/single dose) }\end{array}$ & $\begin{array}{l}\text { Number } \\
\text { of series }\end{array}$ & $\begin{array}{l}\text { Range of } \\
\text { SIB-single dose }\end{array}$ & DFS & LRC & CFS & OS & Acute $\geq$ grade 3 toxicity \\
\hline \multirow[t]{5}{*}{ Menkarios 2007} & 5 & * & Concept: 2 dose levels (SIB): & $1-2$ & $1.5-1.8 \mathrm{~Gy}$ & * & * & * & * & * \\
\hline & & & 49.5/1.5 Gy & & & & & & & \\
\hline & & & 59.4/1.8 Gy & & & & & & & \\
\hline & & & or & & & & & & & \\
\hline & & & 2 series ( $45 / 1.8$ and $59.4 / 1.8 \mathrm{~Gy}$ ) & & & & & & & \\
\hline \multirow[t]{5}{*}{ Salama 2007} & 53 & 14.5 & PTV: 32-60.9 Gy (median: 51.5 Gy) & $1-2$ & $1.65-2.0 \mathrm{~Gy}$ & & $84 \% / 1.5 y$ & $84 \% / 1.5 y$ & $93 \% / 1.5 y$ & Gl: $15 \%$ \\
\hline & & & & & & & & & & Skin: $38 \%$ \\
\hline & & & ENI: 30.6-45 Gy (median: 45 Gy) & & & & & & & Hematologic: 59\% \\
\hline & & & Concept: 3 dose levels: & & & & & & & \\
\hline & & & 41.25/1.65 Gy,45/1.8, 50/2.0 (+/-boost) & & & & & & & \\
\hline \multirow[t]{3}{*}{ Vieillot 2010} & 10 & * & Concept: 2 dose levels: & 1 & 1.5-1.8 Gy & * & * & * & * & * \\
\hline & & & 49.5/1.5 Gy & & & & & & & \\
\hline & & & 59.4/1.8 Gy & & & & & & & \\
\hline \multirow[t]{3}{*}{ Call 2011} & 34 & 22 & PTV: 48.6-57.6 Gy (median: 50.4 Gy) & 1 & $1.28-2.25 \mathrm{~Gy}$ & $80 \% / 3 y$ & & & $87 \% / 3 y$ & Not reported \\
\hline & & & ENI: $38-45$ Gy & & & & & & & \\
\hline & & & No standard concept & & & & & & & \\
\hline \multirow[t]{4}{*}{ Barzan 2011} & 29 & 32 & Concept: 3 dose levels: & 2 & 1.6-1.8 Gy & & $92 / 3 y$ & $91 / 3 y$ & $88 \% / 3 y$ & $\mathrm{Gl}: 7 \%$ \\
\hline & & & 40/1.6 Gy & & & & & & & Skin: $21 \%$ \\
\hline & & & 45/1.8 Gy & & & & & & & Hematologic: $21 \%$ \\
\hline & & & +boost 5.4 Gy (T1/2), 9-14.4 Gy (T3/4) & & & & & & & \\
\hline \multirow[t]{6}{*}{ Kachnic 2012} & 43 & 24 & Concept: T-stage based SIB (2 dose levels) & 1 & 1.5-1.8 Gy & & $95 \% / 2 y$ & $94 \% / 2 y$ & $92 \% / 2 y$ & Gl: $7 \%$ \\
\hline & & & & & & & & & & Skin: $10 \%$ \\
\hline & & & T2NO: 42/1.5 Gy ENI, 50.4/1.8 Gy to PTV & & & & & & & Hematologic: $51 \%$ \\
\hline & & & T3-4N0-3: 45/1.5 Gy ENI, & & & & & & & \\
\hline & & & $50.4 / 1.68$ Gy to lymph nodes $<3 \mathrm{~cm}$ & & & & & & & \\
\hline & & & 54/1.8 Gy to PTV and lymph nodes $>3 \mathrm{~cm}$ & & & & & & & \\
\hline \multirow[t]{3}{*}{ Deenen 2012} & 18 & 28 & 49.5/1.5 Gy ENI & $1-2$ & 1.5-1.8 Gy & & $83 \% / 2 y$ & & & Gl: 0\%, \\
\hline & & & 59.4/1.8 for PTV & & & & & & & Skin: $50 \%$ \\
\hline & & & Boost 5.4/1.8 Gy for macroscopic residual tumor after 5 weeks & & & & & & & Hematologic: $0 \%$ \\
\hline
\end{tabular}


Table 3 Different SIB-IMRT schedules in treatment of anal cancer (Continued)

\begin{tabular}{llll}
\hline Mitchell 2013 & 65 & 19 & PTV: 50-58.8 Gy (median: 54 Gy)
\end{tabular}

1.62-2.0 Gy

$86 \% / 2 y$

$96 \% / 2 y$

Gl: $9 \%$

ENI: 40.5-50.4 Gy (median: 45 Gy)

Hematologic: $3 \%$

Concept: T-stage based SIB (2 dose levels):

T1: 50/2 Gy, 43/1.72 Gy

T2: 54/2, 45/1.67 Gy

T3/4: 58/2, 47/1.62 Gy

$\begin{array}{ll}\text { Present study } 25 \quad 20 \quad & 45 / 1.8 \text { Gy to PTV } \\ & 38 / 1.52 \text { Gy ENI } \\ & 14 / 2 \text { Gy boost to PTV in second series (total: } 59 \text { Gy) }\end{array}$

$2 \quad 1.52-2 \mathrm{~Gy}$

$92 \% / 2 y \quad 92 \% / 2 y$

$92 \% / 2 y$

$88 \% / 2 y$

Skin: 23\%

Hematologic: 16\%

*comparison of different plans, $E N I=$ Elective node irradiation, $F U$ = Follow-up, $G I=$ Gastrointestinal, $P T V=$ Planning target volume. 
tumors (RTOG 98-11, RTOG 0529), we usually give 59 Gy regardless of $\mathrm{T}$ stage with very few exceptions for very small primary tumors.

In our opinion, the concept of two series has two major advantages: Firstly, the single dose to elective nodes is not below 1.52 Gy to $1.8 \mathrm{~Gy}$ and the dose to the GTV can be kept at 2 Gy fractions. Secondly, the boost holds the chance to escalate doses in 2.0 Gy single doses on an individual basis. Limitations of our study are its retrospective design, the limited number of patients and short follow-up. However, we present an easy to use SIB-IMRT schedule and our clinical data and experience suggest that this schedule is safe and efficacious when compared to other published series.

\section{Conclusion}

We present a new SIB-IMRT schedule to treat patients with anal cancer in two series using moderate single doses from 1.5-2.0 Gy with a total dose of 59 Gy in combination with 5FU/MMC. Our results, in terms of loco-regional control and toxicity, are comparable to the results of other studies. Remarkably, the incidence of treatment interruptions was very low. Therefore this schedule appears to be safe and favorable for clinical use. More prospective studies on SIB-IMRT schedules are needed in order to define a standard.

\section{Informed consent}

Written informed consent was obtained from the patient for the publication of this report and any accompanying images.

\section{Competing interests}

On behalf of all authors, the corresponding author states that there is no conflict of interest. Financial disclose: No financial or material support. Level of Incidence: $2 c$.

\section{Authors' contributions}

SJ: data collection, draft of the manuscript. CG,PB,GS,MB: clinical FU, final corrections, SS: statistics, final corrections, OR: idea, clinical FU, draft of the manuscript. All authors were involved in the treatment of the included patients. All authors read and approved the final manuscript.

\section{Author details}

${ }^{1}$ Departments of Radiation Oncology, University Hospital Zurich, Rämistrasse 100, CH-8091 Zurich, Switzerland. ${ }^{2}$ Clinic of Gastroenterology and Hepatology, University Hospital Zurich, Zurich, Switzerland.

Received: 20 December 2013 Accepted: 31 August 2014 Published: 8 September 2014

\section{References}

1. Johnson LG, Madeleine MM, Newcomer LM, Schwartz SM, Daling JR: Anal cancer incidence and survival: the surveillance, epidemiology, and end results experience, 1973-2000. Cancer 2004, 101(2):281-288.

2. Nigro ND, Vaitkevicius VK, Considine B Jr: Combined therapy for cancer of the anal canal: a preliminary report. Dis Colon Rectum 1974, 17(3):354-356.

3. Bartelink H, Roelofsen F, Eschwege F, Rougier P, Bosset JF, Gonzalez DG, Peiffert D, van Glabbeke M, Pierart M: Concomitant radiotherapy and chemotherapy is superior to radiotherapy alone in the treatment of locally advanced anal cancer: results of a phase III randomized trial of the European Organization for Research and Treatment of Cancer Radiotherapy and Gastrointestinal Cooperative Groups. J Clin Oncol 1997, 15(5):2040-2049.

4. Epidermoid anal cancer: results from the UKCCCR randomised trial of radiotherapy alone versus radiotherapy, 5-fluorouracil, and mitomycin. UKCCCR Anal Cancer Trial Working Party. UK Co-ordinating Committee on Cancer Research. Lancet 1996, 348(9034):1049-1054.

5. Ajani JA, Winter KA, Gunderson LL, Pedersen J, Benson AB 3rd, Thomas CR Jr, Mayer RJ, Haddock MG, Rich TA, Willett C: Fluorouracil, mitomycin, and radiotherapy vs fluorouracil, cisplatin, and radiotherapy for carcinoma of the anal canal: a randomized controlled trial. JAMA 2008, 299(16):1914-1921.

6. Milano MT, Jani AB, Farrey KJ, Rash C, Heimann R, Chmura SJ: Intensitymodulated radiation therapy (IMRT) in the treatment of anal cancer: toxicity and clinical outcome. Int J Radiat Oncol Biol Phys 2005, 63(2):354-361

7. Bazan JG, Hara W, Hsu A, Kunz PA, Ford J, Fisher GA, Welton ML, Shelton A, Kapp DS, Koong AC, Goodman KA, Chang DT: Intensitymodulated radiation therapy versus conventional radiation therapy for squamous cell carcinoma of the anal canal. Cancer 2011, 117(15):3342-3351.

8. Salama JK, Salama JK, Mell LK, Schomas DA, Miller RC, Devisetty K, Jani AB, Mundt AJ, Roeske JC, Liauw SL, Chmura SJ: Concurrent chemotherapy and intensity-modulated radiation therapy for anal canal cancer patients: a multicenter experience. J Clin Oncol 2007, 25(29):4581-4586.

9. Chuong MD, Freilich JM, Hoffe SE, Fulp W, Weber JM, Almhanna K, Dinwoodie W, Rao N, Meredith KL, Shridhar R: Intensity-modulated radiation therapy vs. 3D conformal radiation therapy for squamous cell carcinoma of the anal canal. Gastrointest Cancer Res 2013, 6(2):39-45.

10. Menkarios C, Azria D, Laliberté B, Moscardo CL, Gourgou S, Lemanski C, Dubois JB, Aillères N, Fenoglietto P: Optimal organ-sparing intensitymodulated radiation therapy (IMRT) regimen for the treatment of locally advanced anal canal carcinoma: a comparison of conventional and IMRT plans. Radiat Oncol 2007, 2:41.

11. Brooks CJ, Lee YK, Aitken K, Hansen VN, Tait DM, Hawkins MA: Organ-sparing Intensity-modulated radiotherapy for anal cancer using the ACTII schedule: a comparison of conventional and intensity-modulated radiotherapy plans. Clin Oncol ( $R$ Coll Radiol) 2013, 25(3):155-161.

12. Mitchell MP, Abboud M, Eng C, Beddar AS, Krishnan S, Delclos ME Crane $\mathrm{CH}$, Das $\mathrm{P}$ : Intensity-modulated radiation therapy with concurrent chemotherapy for anal cancer: outcomes and toxicity. Am J Clin Oncol 2013.

13. Kachnic LA, Tsai HK, Coen JJ, Blaszkowsky LS, Hartshorn K, Kwak EL, Willins JD, Ryan DP, Hong TS: Dose-painted intensity-modulated radiation therapy for anal cancer: a multi-institutional report of acute toxicity and response to therapy. Int J Radiat Oncol Biol Phys 2012, 82(1):153-158.

14. James RD, Glynne-Jones R, Meadows HM, Cunningham D, Myint AS, Saunders MP, Maughan T, McDonald A, Essapen S, Leslie M, Falk S, Wilson C, Gollins S, Begum R, Ledermann J, Kadalayil L, SebagMontefiore D: Mitomycin or cisplatin chemoradiation with or without maintenance chemotherapy for treatment of squamous-cell carcinoma of the anus (ACT II): a randomised, phase 3, open-label, $2 \times 2$ factorial trial. Lancet Oncol 2013, 14(6):516-524.

15. Kachnic LA, Winter K, Myerson RJ, Goodyear MD, Willins J, Esthappan J, Haddock MG, Rotman M, Parikh PJ, Safran H, Willett CG: RTOG 0529: a phase 2 evaluation of dose-painted intensity modulated radiation therapy in combination with 5 -fluorouracil and mitomycin-C for the reduction of acute morbidity in carcinoma of the anal canal. Int J Radiat Oncol Biol Phys 2013, 86(1):27-33.

16. Oehler-Jänne C, Seifert B, Lütolf UM, Studer G, Glanzmann C, Ciernik IF: Clinical outcome after treatment with a brachytherapy boost versus external beam boost for anal carcinoma. Brachytherapy 2007, 6(3):218-226.

17. Graf R, Wust P, Hildebrandt B, Gögler H, Ullrich R, Herrmann R, Riess $H$, Felix R: Impact of overall treatment time on local control of anal cancer treated with radiochemotherapy. Oncology 2003, 65(1):14-22. 
18. Constantinou EC, Daly W, Fung CY, Willett CG, Kaufman DS, DeLaney TF: Time-dose considerations in the treatment of anal cancer. Int J Radiat Oncol*Bio*Phys 1997, 39(3):651-657.

19. Deenen MJ, Dewit L, Boot H, Beijnen JH, Schellens JH, Cats A:

Simultaneous integrated boost-intensity modulated radiation therapy with concomitant capecitabine and mitomycin C for locally advanced anal carcinoma: a phase 1 study. Int I Radiat Oncol Biol Phys 2013, 85(5):e201-e207.

doi:10.1186/1748-717X-9-199

Cite this article as: Janssen et al:: Clinical experience of SIB-IMRT in anal cancer and selective literature review. Radiation Oncology 2014 9:199.

\section{Submit your next manuscript to BioMed Central and take full advantage of:}

- Convenient online submission

- Thorough peer review

- No space constraints or color figure charges

- Immediate publication on acceptance

- Inclusion in PubMed, CAS, Scopus and Google Scholar

- Research which is freely available for redistribution 